Cardiopulmonary

Support

and Physiology

\title{
Preserved myocardial blood flow and oxygen supply- demand balance with active coronary perfusion during simulated off-pump coronary artery bypass grafting
}

Satoshi Muraki, MD, PhD

Cullen D. Morris, MD

Jason M. Budde, MD

Rachel N. Otto, BS

Zhi-Qing Zhao, MD, PhD

John D. Puskas, MD

Robert A. Guyton, MD

Jakob Vinten-Johansen, PhD

From the Section of Cardiothoracic Surgery, Carlyle Fraser Heart Center, Emory University School of Medicine, Atlanta, Ga.

Supported by the Carlyle Fraser Heart Center of Crawford Long Hospital, Emory University, and a Scientific Development Award (Z-QZ) and a Grant-in-Aid (JV-J) from the National American Heart Association.

Received for publication Dec 20, 2000; revisions requested April 17, 2001; revisions received May 14, 2001; accepted for publication June 15, 2001.

Address for reprints: Jakob Vinten-Johansen, $\mathrm{PhD}$, Cardiothoracic Research Laboratory, Carlyle Fraser Heart Center, 550 Peachtree Street NE, Atlanta, GA 30308-2225 (E-mail: jvinten@emory.edu).

J Thorac Cardiovasc Surg 2002;123:53-62

Copyright (C) 2002 by The American Association for Thoracic Surgery

$0022-5223 / 2002 \$ 35.00+0 \quad \mathbf{1 2 / 1 / 1 1 8 5 0 2}$

doi:10.1067/mtc.2002.118502

Background: During off-pump coronary artery bypass surgery, concern remains about the possible myocardial injury associated with the transient occlusion and stabilization of the target vessels. Although intraluminal shunts are used to avoid ischemia during graft anastomosis, blood flow through the shunts can be affected by upstream pressure and inherent resistance, resulting in reduced blood flow during hypotension or severe proximal stenosis.

Methods: In anesthetized dogs regional myocardial blood flow (microspheres), oxygen consumption, lactate extraction, and systolic shortening (sonomicrometry) were measured in the myocardium served by the left anterior descending coronary artery with native perfusion after interposition of a $2.25-\mathrm{mm}$ shunt $(\geq 90 \%$ of left anterior descending diameter) and during active coronary perfusion with a constant flow pump. Measurements were made under normotension and hypotension produced by partial caval occlusion to reduce arterial pressure by $50 \%$.

Results: Interposition of the shunt reduced blood flow by $67.8 \%$, regional oxygen delivery by $59.8 \%$, and systolic shortening by $45.6 \%$ relative to baseline, but lactate extraction $(31.0 \%$ vs $31.2 \%)$ and oxygen supply-consumption $\left(\mathrm{O}_{2} \mathrm{~S} /\right.$ myocardial oxygen consumption ratio, $2.7 \pm 0.5$ vs $2.6 \pm 0.5$ ) were comparable with baseline values. Hypotension further decreased these physiologic values and was associated with local lactate production (-67.4\% extraction) and decreased $\mathrm{O}_{2} \mathrm{~S} /$ myocardial oxygen consumption ratio $(1.3 \pm 0.1)$. Active coronary perfusion was associated with regional blood flow, oxygen delivery, systolic shortening, and lactate extraction comparable with baseline values. In contrast to the shunt, active perfusion maintained myocardial flow, oxygen delivery, and lactate extraction during hypotension and normalized the $\mathrm{O}_{2} \mathrm{~S} /$ myocardial oxygen consumption ratio, although systolic shortening decreased as a result of ventricular unloading.

Conclusion: Intraluminal shunts may impede oxygen delivery to the target myocardium, which precipitates regional ischemia during transient hypotension. Active coronary perfusion provides adequate oxygen supply independent of systemic blood pressure. 

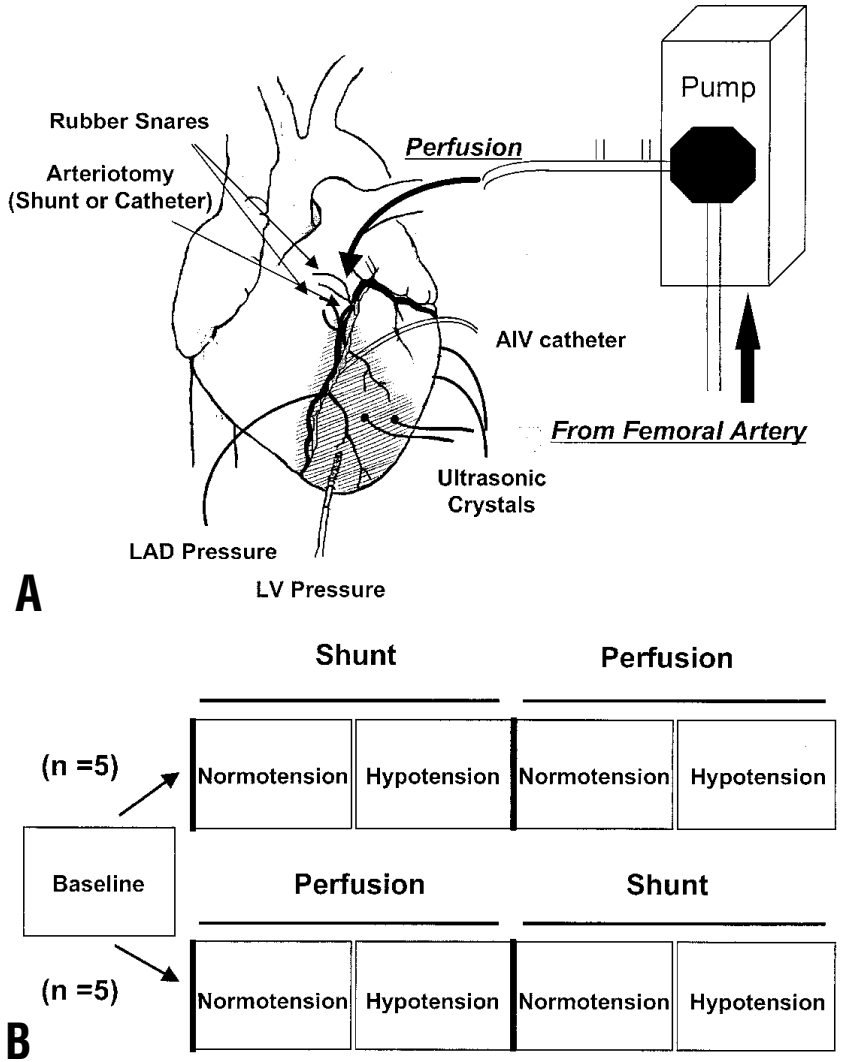

Fig 1. A, Diagram of the surgical preparation and LAD perfusion circuit. After the baseline measurements, the LAD was secured either with intracoronary shunts or an intraluminal cannula distal to the first diagonal branch to perfuse the target area (hatched area) under different conditions. $L V$, Left ventricular. $B$, Experimental protocol. The order of the 2 experimental interventions was randomized (shunt series first, $n=5$; active-perfusion series first, $n=5$ ) to minimize the study limitation, and a total of 5 consecutive data points were obtained in each dog. Shunt, Intracoronary shunt; Perfusion, active perfusion.

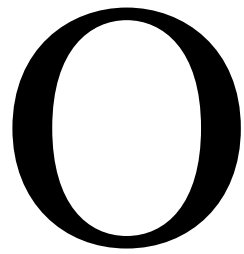

ff-pump coronary artery bypass (OPCAB) grafting has recently gained large acceptance with good short-term results. ${ }^{1,2}$ However, OPCAB usually requires a period of target coronary artery occlusion to achieve adequate visibility during distal anastomosis. This transient ischemic period may be superimposed on preexisting ischemia of varying degrees and may produce myocardial damage to the target segment. ${ }^{3,4}$ In addition, retraction and stabilization maneuvers during OPCAB often cause hemodynamic instability and systemic hypotension, especially when the hearts are displaced vertically for exposure of lateral and posterior branches, ${ }^{5,6}$ which may necessitate prompt conversion to conventional on-pump coronary artery bypass grafting. In this regard hemodynamic instability during displacement of the heart has been addressed with mechanical support systems for either the left ${ }^{7}$ or right ${ }^{8}$ ventricle. Several clinical studies have shown the effectiveness of intracoronary shunts to maintain myocardial perfusion to avoid ischemia of target vessels during routine $\mathrm{OPCAB} .{ }^{9-11}$ However, it is unclear how the adequacy of blood flow is affected by intracoronary shunts when systemic blood pressure, which drives coronary flow, is reduced by means of retraction and stabilization maneuvers during $\mathrm{OPCAB}$.

In this regard we recently introduced the concept of perfusion-assisted direct coronary artery bypass (PADCAB), ${ }^{12}$ a novel technique by which to perfuse grafted vessels directly during multivessel OPCAB by a computer-controlled blood-delivery system. This technique enables active perfusion of selected target myocardium independent of systemic blood pressure, which contrasts with passive blood flow provided by intraluminal shunts or mechanical ventricular support systems. PADACB has the potential to avoid ischemia and its physiologic consequences during $\mathrm{OPCAB}$ by maintaining adequate perfusion, even during systemic hypotension.

Accordingly, the present study tests the hypotheses that intracoronary shunts provide inadequate blood flow during target coronary occlusion, that this inadequate delivery of blood flow is exacerbated during hypotension, and that active perfusion maintains adequate blood-flow delivery during normal blood pressure and systemic hypotension.

\section{Materials and Methods \\ Experimental Preparation}

All animals received humane care in compliance with the "Guide for the Care and Use of Laboratory Animals" prepared by the Institute of Laboratory Animal Resources, National Research Council, and published by the National Academy Press (revised 1996). Ten healthy mongrel dogs of either sex weighing 23.8 to $33.6 \mathrm{~kg}$ (average weight, $29.8 \pm 1.0 \mathrm{~kg}$ ) were initially anesthetized with intravenous $2.5 \%$ thiopental $(20 \mathrm{mg} / \mathrm{kg})$, followed by constant infusion of fentanyl citrate $\left(0.4 \mu \mathrm{g} \cdot \mathrm{kg}^{-1} \cdot \mathrm{min}^{-1}\right)$ and diazepam $\left(0.003 \mathrm{mg} \cdot \mathrm{kg}^{-1} \cdot \mathrm{min}^{-1}\right)$ during the experiment. Each dog was endotracheally intubated and mechanically ventilated to maintain a $\mathrm{PaO}_{2}$ of greater than $100 \mathrm{~mm} \mathrm{Hg}$, a $\mathrm{PaCO}_{2}$ of 35 to $45 \mathrm{~mm} \mathrm{Hg}$, and a $\mathrm{pH}$ of 7.35 to 7.45. Metabolic acidemia was corrected with sodium bicarbonate infusion as needed. Polyethylene catheters were inserted into the femoral artery bilaterally, with one side being used for monitoring systemic arterial blood pressure and microsphere reference sampling and the contralateral side being used as an arterial blood source for the coronary arterial perfusion circuit during the active perfusion component of the experiment (Fig 1, A). The chest was opened by means of a lateral thoracotomy at the fifth intercostal space, the inferior vena cava was looped with an umbilical tape, and the heart was suspended with a pericardial cradle. A Millar MPC-500 temperature-compensating solid-state catheter (Millar Instruments, Houston, Tex) was placed in the left ventricular cavity through an apical stab wound to mea- 
sure instantaneous left ventricular pressure. A polyethylene catheter was inserted into the left atrium for injection of colored microspheres. A proximal portion of the left anterior descending coronary artery (LAD) was dissected free and encircled loosely with 2 rubber vessel loops for snaring around an intracoronary shunt or around the intraluminal perfusion cannula. Pairs of 5$\mathrm{MHz}$ piezoelectric ultrasonic crystals 2.5 to $3.0 \mathrm{~mm}$ in diameter were placed in the subendocardium within the area perfused by the LAD (target area) and the left circumflex coronary artery (LCx; normal area) to measure instantaneous segmental dimensions with a sonomicrometer (model 120; Triton Technology, San Diego, Calif). A model SPC-320 2Fr solid-state pressure transducer (Millar Instruments) was inserted into a small right ventricular branch of the LAD distal to the site of arteriotomy to measure instantaneous LAD intracoronary pressure (Fig 1, $A$ ). The position of the transducer catheter did not interfere with LAD blood flow. A sampling catheter was introduced by means of direct puncture of the anterior interventricular vein (AIV) to sample venous blood draining exclusively from the region perfused by the LAD. The dogs were systemically heparinized with $300 \mathrm{U} / \mathrm{kg}$ heparin sodium supplemented with $300 \mathrm{U} / \mathrm{kg}$ every 90 minutes.

\section{Experimental Protocol}

The protocol is schematically presented in Fig 1, B. Hemodynamic data and blood samples were obtained, and colored microspheres were injected at baseline. After reversible ligation of the LAD, an arteriotomy was performed distal to the occlusion through which either a 2-mm-diameter cannula (DLPlegia Highflow Vessel Cannulae; Medtronic DLP, Grand Rapids, Mich) or a 2.25-mm intraluminal shunt (FLOTHRU; Bio-Vascular, Inc, Saint Paul, Minn) was inserted. The outer diameter of the shunt was $90 \%$ of the LAD diameter at the point of insertion. For the intracoronary shunt series, 2 rubber snares were tightened around the proximal and distal ends of the shunt device after insertion into the arteriotomy. In the shunt series data were collected under normotensive conditions (Shunt-Normo group) and under systemic hypotension (ShuntHypo group) created by partial snaring of the inferior vena cava to $50 \%$ of baseline blood pressure. In the active-perfusion series the LAD cannula was attached to a delivery line from a constantvolume nonpulsatile pump (Myocardial Protection System cardioplegia and perfusion delivery system; Quest Medical Inc, Allen, Tex), and perfusion was immediately established with continuous withdrawal of femoral arterial blood (Fig 1, A). LAD systolic pressure was immediately matched to left ventricular systolic pressure by adjusting the flow rate, and the flow was considered to reach equilibration once the blood-flow rate and intracoronary pressure became stable. The compliance in the bladder-based perfusion system avoided the marked decrease in diastolic pressure observed with positive displacement perfusion systems. Thereafter, the flow was kept constant throughout the active-perfusion experiments. Data were again collected under normotensive (Perfusion-Normo group) and hypotensive (Perfusion-Hypo group) conditions. The dogs were allowed to stabilize for 20 to 30 minutes after each intervention. The order of shunt or active-perfusion series was randomized (Fig 1, B). During active perfusion, colored microspheres were injected into the proximal portion of the perfusion line and sampled distally at $3 \mathrm{~mL} / \mathrm{min}$ to determine myocardial blood flow specifi- cally in the area at risk to avoid loss of microspheres by adherence to pump components. The pump blood-flow rate was increased accordingly to compensate for reference-sample withdrawal from the catheter. Analysis of the perfusion tubing, shunts, and coronary catheters showed no adherent microspheres.

\section{Data Collection and Analysis}

Hemodynamic data, including left ventricular, systemic arterial (femoral arterial), and LAD pressures, and segmental length data were acquired during a 10 -second period of respiratory apnea. The pressure-rate product was calculated from left ventricular systolic pressure multiplied by heart rate. The data from each channel were digitized and processed with computer algorithms by using an interactive videographics program (SPECTRUM; Wake Forest University, Winston-Salem, NC), as described previously. ${ }^{14}$ Percentage of segmental shortening (SS\%) and segmental stroke work (SW) were determined, as previously described.

\section{Regional Myocardial Blood Flow}

Regional myocardial blood flow (RMBF) with 0.15 (in-line injection) to 2.0 (left atrial injection) million $15-\mu \mathrm{m}$ color-labeled microspheres (Triton Technology, San Diego, Calif) was calculated by using the reference-sampling method, as previously described. Reference samples were withdrawn from the femoral artery or the perfusion line at a constant rate for 3 minutes. Postexperimental myocardial tissue and reference blood samples were analyzed with a spectrophotometer (DU7400; Beckman, Fullerton, Calif). Blood flow was calculated in the normal epicardium, normal endocardium, target epicardium, and target endocardium, as follows:

$$
\mathrm{RMBF}=\left(\mathrm{C}_{\mathrm{T}} \mathrm{F}_{\mathrm{R}} / \mathrm{C}_{\mathrm{R}}\right) / \mathrm{W}_{\mathrm{T}},
$$

where $C_{T}$ and $C_{R}$ are the absorbances from dispersed microspheres in the tissue and reference blood samples, respectively. $F_{R}$ is the reference flow rate, and $\mathrm{W}_{\mathrm{T}}$ is the total weight of the tissue sample in grams. Blood flow was also integrated over subepicardial and subendocardial regions to give transmural blood flow. Results are expressed as milliliters per minute per gram of tissue.

\section{Regional Oxygen and Lactate Extraction}

Arterial and local coronary venous oxygen content and blood lactate concentration were measured with a blood gas and metabolite analyzer (Stat Profile M; Nova Biomedical, Waltham, Mass). The percentage of regional myocardial oxygen extraction was calculated from the arterial-AIV oxygen content difference divided by arterial oxygen content. Likewise, the percentage of regional transmyocardial lactate extraction was calculated from the arterial-AIV lactate difference divided by the arterial lactate concentration.

\section{Regional Oxygen Consumption and Delivery}

Regional myocardial oxygen consumption $\left(\mathrm{MVO}_{2}\right)$ of the LAD myocardium was calculated with the arterial-AIV oxygen content difference and the transmurally integrated myocardial blood flow from the target zone, as previously described, ${ }^{13}$ and is expressed in milliliters of oxygen per minute per gram. Likewise, regional oxygen delivery $\left(\mathrm{O}_{2}\right.$ delivery) was calculated with the arterial oxygen content and the transmurally integrated blood flow from the target zone. These measurements and calculations have been previously 
TABLE 1. Hemodynamic data at baseline and during the intracoronary shunt and active-perfusion series

\begin{tabular}{|c|c|c|c|c|c|}
\hline & \multirow[b]{2}{*}{ Baseline } & \multicolumn{2}{|c|}{ Shunt } & \multicolumn{2}{|c|}{ Perfusion } \\
\hline & & Normotension & Hypotension & Normotension & Hypotension \\
\hline HR (beats/min) & $102.4 \pm 6.2$ & $\begin{array}{r}125.0 \pm 7.7 \\
\left({ }^{*} P=.02\right)\end{array}$ & $\begin{array}{c}171.1 \pm 7.7\left({ }^{*} P=.0001\right. \\
\dagger P=.0002)\end{array}$ & $117.4 \pm 8.1$ & $\begin{array}{c}166.2 \pm 9.3{ }^{*} P=.0001 ; \\
\dagger P=.0003)\end{array}$ \\
\hline $\operatorname{LVSP}(\mathrm{mm} \mathrm{Hg})$ & $90.0 \pm 2.4$ & $84.4 \pm 3.4$ & $\begin{array}{c}46.1 \pm 2.8\left({ }^{*} P=.0001\right. \\
+P=.001)\end{array}$ & $82.7 \pm 3.3$ & $\begin{array}{c}41.0 \pm 2.0\left({ }^{*} P=.0001 ;\right. \\
+P=.0001)\end{array}$ \\
\hline $\operatorname{LVEDP}(\mathrm{mm} \mathrm{Hg})$ & $7.1 \pm 0.4$ & $7.2 \pm 0.3$ & $\begin{array}{c}5.0 \pm 0.6\left({ }^{*} P=.005\right. \\
+P=.003)\end{array}$ & $7.2 \pm 0.3$ & $\begin{array}{c}3.8 \pm 0.4\left({ }^{*} P=.0001 ;\right. \\
\dagger P=.0001)\end{array}$ \\
\hline $\operatorname{MAP}(\mathrm{mm} \mathrm{Hg})$ & $71.4 \pm 2.0$ & $68.5 \pm 3.6$ & $\begin{array}{c}34.8 \pm 2.4\left({ }^{*} P=.0001\right. \\
\dagger P=.0001)\end{array}$ & $68.9 \pm 3.2$ & $\begin{array}{c}37.1 \pm 2.4\left({ }^{*} P=.0001 ;\right. \\
+P=.0001)\end{array}$ \\
\hline $\operatorname{MLADP}(\mathrm{mm} \mathrm{Hg})$ & $69.1 \pm 2.2$ & $63.3 \pm 4.8$ & $\begin{array}{c}36.7 \pm 4.0\left({ }^{*} P=.0001\right. \\
\quad+P=.0001)\end{array}$ & $74.9 \pm 3.8$ & $67.6 \pm 2.3$ \\
\hline PRP (mm Hg · beats/min) & $9211 \pm 581$ & $10,834 \pm 946$ & $7537 \pm 717(† P=.008)$ & $9690 \pm 752$ & $\begin{array}{c}6953 \pm 637\left({ }^{*} P=.01\right. \\
+P=.008)\end{array}$ \\
\hline$+\mathrm{dP} / \mathrm{dt}(\mathrm{mm} \mathrm{Hg} / \mathrm{s})$ & $1142 \pm 81$ & $948 \pm 63$ & $\begin{array}{c}590 \pm 48\left({ }^{*} P=.0001\right. \\
\dagger P=.0001)\end{array}$ & $1005 \pm 70$ & $\begin{array}{c}532 \pm 44\left({ }^{*} P=.0001 ;\right. \\
+P=.0001)\end{array}$ \\
\hline$-\mathrm{dP} / \mathrm{dt}(-\mathrm{mm} \mathrm{Hg} / \mathrm{s})$ & $1071 \pm 55$ & $960 \pm 64$ & $\begin{array}{l}402 \pm 37\left({ }^{*} P=.0001\right. \\
\quad+P=.0001)\end{array}$ & $937 \pm 69$ & $\begin{array}{c}338 \pm 35\left(^{*} P=.0001\right. \\
\dagger P=.0001)\end{array}$ \\
\hline
\end{tabular}

Values are given as means \pm SEM.

$H R$, Heart rate; $L V S P$, left ventricular systolic pressure; $L V E D P$, left ventricular end-diastolic pressure; MAP, mean arterial pressure; MLADP, mean LAD pressure; $P R P$, pressure-rate product; $d P / d t$, first derivative of left ventricular pressure.

${ }^{*} P$ value versus baseline values.

$\dagger P$ value versus normotension in the same series.

TABLE 2. RMBF in target (LAD) and normal (LCx) myocardium

\begin{tabular}{|c|c|c|c|c|}
\hline & \multicolumn{2}{|c|}{ Target zone } & \multicolumn{2}{|c|}{ Normal zone } \\
\hline & Epicardium & Endocardium & Epicardium & Endocardium \\
\hline Baseline & $0.885 \pm 0.121$ & $0.697 \pm 0.094$ & $0.843 \pm 0.105$ & $0.855 \pm 0.093$ \\
\hline \multicolumn{5}{|l|}{ Shunt } \\
\hline Normotension & $0.299 \pm 0.087\left({ }^{*} P=.002\right)$ & $0.214 \pm 0.045\left({ }^{*} P=.0004\right)$ & $0.777 \pm 0.093$ & $0.747 \pm 0.084$ \\
\hline Hypotension & $0.151 \pm 0.028\left({ }^{*} P=.0001\right)$ & $\begin{array}{c}0.097 \pm 0.027\left({ }^{*} P=.0001\right. \\
\dagger P=.04)\end{array}$ & $\begin{array}{c}0.245 \pm 0.056\left({ }^{*} P=.0002\right. \\
+P=.0002)\end{array}$ & $\begin{array}{c}0.169 \pm 0.041\left({ }^{*} P=.0001\right. \\
\dagger P=.0001)\end{array}$ \\
\hline \multicolumn{5}{|l|}{ Perfusion } \\
\hline Normotension & $1.243 \pm 0.142$ & $1.209 \pm 0.172(* P=.02)$ & - & - \\
\hline Hypotension & $0.918 \pm 0.089$ & $1.103 \pm 0.154\left({ }^{*} P=.04\right)$ & - & - \\
\hline
\end{tabular}

Values are means \pm SEM and expressed as milliliters per minute per gram of tissue. Blood flow in normal zone is absent because of local delivery of microspheres to the target area through the perfusion cannula in the perfusion series.

${ }^{*} P$ value versus baseline.

$\dagger P$ value versus normotension in the same series.

validated. ${ }^{13}$ The regional oxygen supply/consumption ratio $\left(\mathrm{O}_{2} \mathrm{~S} / \mathrm{MVO}_{2}\right)$ was also calculated. Under normal conditions, oxygen supply exceeds consumption (ratio $>1$ ), and a ratio approximating unity indicates a potential oxygen supply/consumption mismatch (consumption limited by supply).

\section{Statistical Analysis}

Linear data were analyzed by means of 1-way analysis of variance for repeated measures to identify time-dependent (intervention) interactions. If significant interactions were found, then further pairwise analysis was performed by using post hoc analysis to locate the source of the differences. A $P$ value of less than .05 was considered significant, and means \pm SEM are reported.

\section{Results \\ Hemodynamic Data}

Hemodynamic data during the course of the experiment are shown in Table 1. There were no significant differences among the 3 groups at each normotensive condition in any of the hemodynamic variables, except that the heart rate in the Shunt-Normo group was significantly $(P=.03)$ greater 

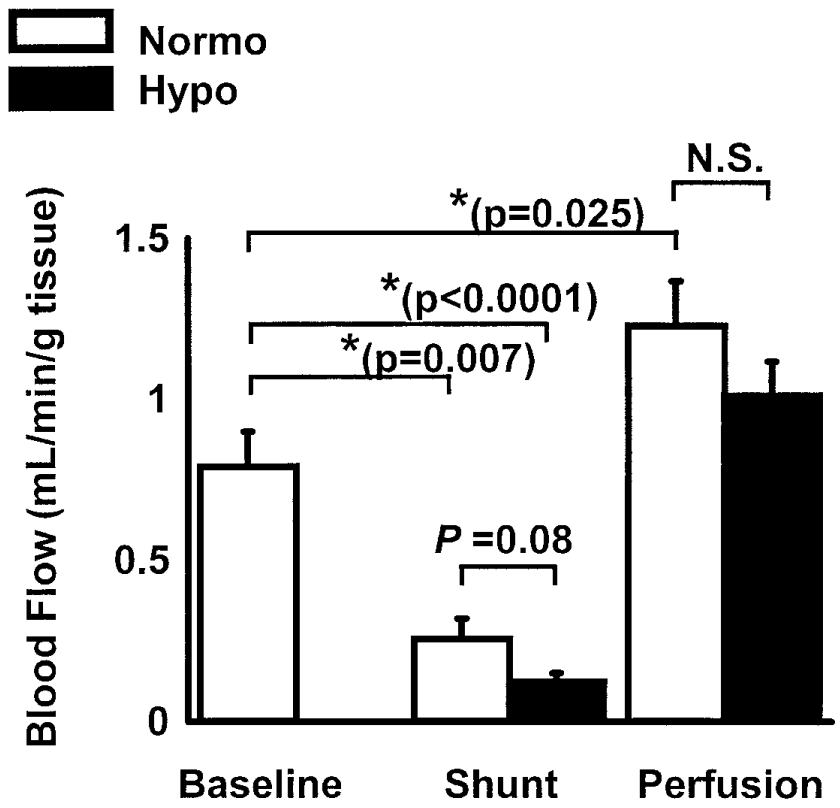

Fig 2. Transmural myocardial blood flow in the target myocardium under the 5 different experimental conditions. Normo, Normotension; Hypo, hypotension; Shunt, intracoronary shunt; Perfusion, active perfusion; NS, not significant. ${ }^{*} P<.05$ between the indicated groups.

compared with that at baseline. Partial occlusion of the inferior vena cava effectively caused systemic hypotension, as clearly shown in left ventricular systolic pressure $(45.4 \%$ and $50.4 \%$ reduction from the Shunt-Normo and PerfusionNormo groups, respectively) or in mean femoral arterial pressure $(49.2 \%$ and $46.2 \%$ reduction from the ShuntNormo and Perfusion-Normo groups, respectively). Left ventricular end-diastolic pressure also decreased significantly during hypotension in both the shunt $(P=.005)$ and the perfusion $(P<.0001)$ series. In addition, the partial caval occlusion caused a decrease in the peak positive and negative first derivative of left ventricular pressure. Systemic hypotension was associated with a significant decrease $(P=.0001)$ in mean LAD pressure $(42.0 \%$ decrease from the normotension value) in the Shunt-Hypo group but only decreased by $9.7 \%$ from the Normotension group in the Perfusion-Hypo group.

\section{Regional Myocardial Blood Flow}

Results of RMBF in the subepicardial and subendocardial regions both from the target and normal myocardium measured by means of colored microspheres are summarized in Table 2. Insertion of the intracoronary shunt was associated with a decrease in blood flow to the subepicardial $(P=$ $.0015)$ and subendocardial $(P=.0004)$ regions of the target zone compared with the baseline values, despite normal arterial pressure. Concomitant systemic hypotension with

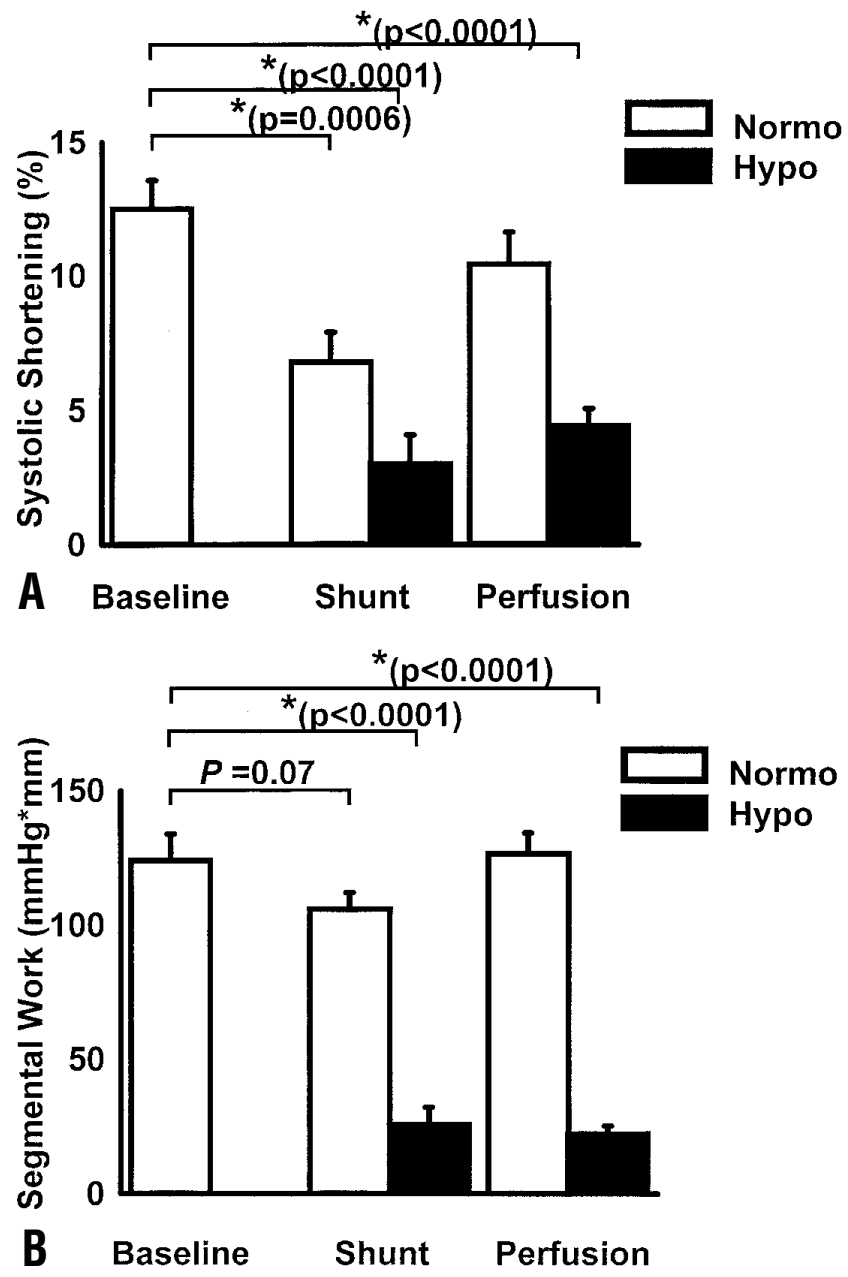

Fig 3. A, Systolic shortening in the target (LAD) zone under the 5 different conditions. Normo, Normotension; Hypo, hypotension; Shunt, intracoronary shunt; Perfusion, active perfusion. B, Segmental work in the target (LAD) zone under the 5 different conditions. Normo, Normotension; Hypo, hypotension; Shunt, intracoronary shunt; Perfusion, active perfusion. ${ }^{*} P<.05$ between the indicated groups.

the intracoronary shunt in place (Shunt-Hypo group) caused a further significant decrease in RMBF in the target zone, with the greater decrease being in the subendocardial region $(P=.0405)$. In contrast, RMBF in the target zone in the Perfusion-Normo group tended to be higher than the baseline values in the subepicardial region, whereas RMBF in the subendocardial region was significantly greater $(P=$ .02). During systemic hypotension (Perfusion-Hypo group), $\mathrm{RMBF}$ in both the subepicardial and subendocardial regions were unchanged from the preceeding normotensive values. Fig 2 shows the transmurally integrated blood flows to the target zone. Interposition of the intracoronary shunt was associated with a significant decrease $(P=.0007)$ in transmural RMBF in the normotensive condition (averaging 


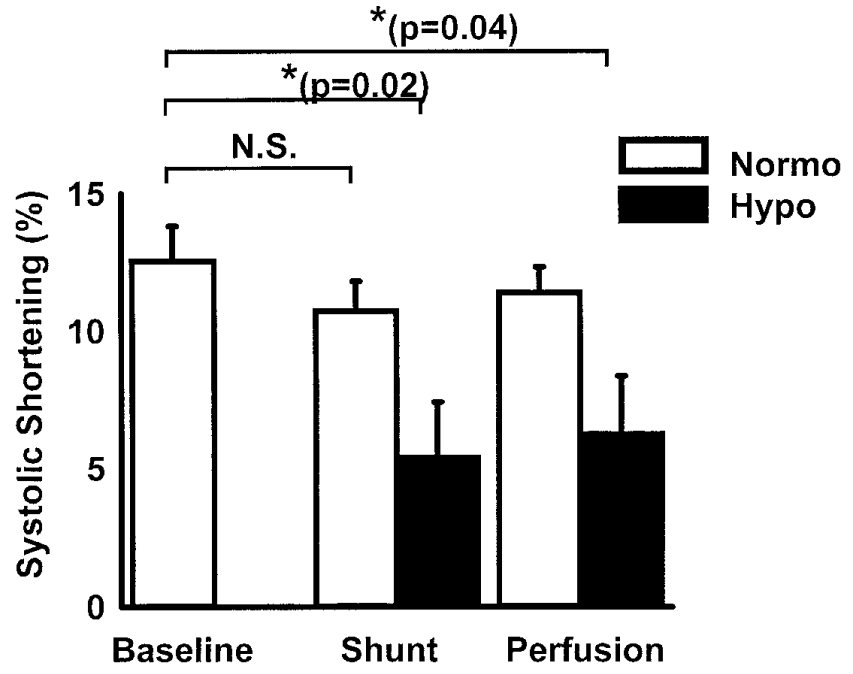

Fig 4. Systolic shortening in the normal (LCx) zone under the 5 different conditions. Normo, Normotension; Hypo, hypotension; Shunt, intracoronary shunt; Perfusion, active perfusion; NS, not significant. ${ }^{*} \boldsymbol{P}<.05$ between the indicated groups.

$32.2 \%$ of baseline). Although not statistically significant, systemic hypotension with the intracoronary shunt caused a further decrease in transmural RMBF $(P=.08$ vs ShuntNormo group). In contrast, transmural RMBF with active perfusion during normotension was significantly greater $(P$ $=.02$ ) than baseline values. Transmural RMBF did not significantly change from this value, with hypotension consistent with blood flow maintained by the perfusion system.

Blood flow to the normally perfused LCx zone showed no significant changes during the normotensive condition when the intracoronary shunt was inserted into the LAD (Table 2). However, systemic hypotension was associated with a $68.5 \%$ reduction in RMBF in the subepicardial region and a 77.4\% reduction in RMBF in the subendocardial region relative to the previous normotensive state.

\section{Segmental Function}

Segmental function in the target zone decreased with interposition of the shunt under normal blood pressure (Fig 3). SS\% decreased more than SW because of a rightward shift in the systolic trajectory indicative of some degree of paradoxical bulging during systole followed by contraction. However, hypotension with the shunt in place was associated with approximately a 70\% reduction in both SS\% and SW (Fig 3). Active perfusion restored regional function to baseline values (Fig 3), although hypotension induced by partial caval occlusion was associated with a similar decrease in segmental function, as seen with the shunt. However, this was not coincident with a decrease in blood flow, as was observed with the shunt. Moreover, SS\% in the noninvolved zone in the Shunt-Normo and Perfusion-Normo groups were similar to

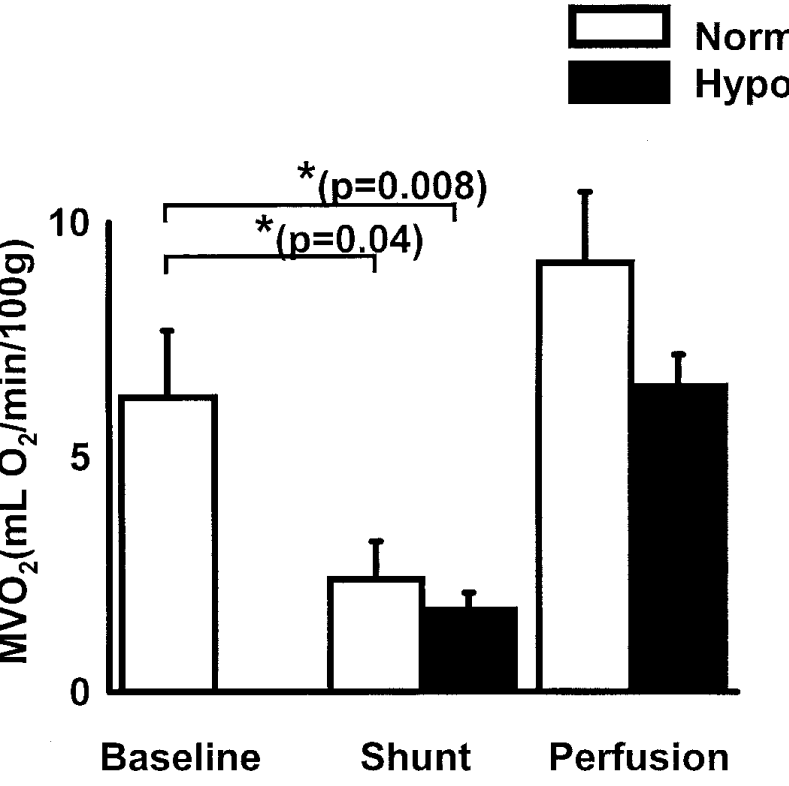

Fig 5. Regional myocardial oxygen consumption under the $\mathbf{5}$ different conditions. Normo, Normotension; Hypo, hypotension; Shunt, intracoronary shunt; Perfusion, active perfusion. ${ }^{*} P<.05$ between the indicated groups.

the baseline values (Fig 4). Hypotension induced by partial caval occlusion was equally associated with a decrease in SS\% and segment work (Fig 4), suggesting that part of the decrease in function was caused by ventricular unloading.

\section{Regional Oxygen and Lactate Extraction in the Target Myocardium}

Results of LAD myocardial oxygen extraction and lactate extraction in the target myocardium are summarized in Table 3. Segmental oxygen extraction in the target zone did not change with interposition of the intracoronary shunt under normotensive conditions, although blood flow decreased by an average of $67 \%$ from baseline values. However, concomitant hypotension increased extraction by $72 \%$ from baseline values. In contrast, there was no change in regional oxygen extraction in the active-perfusion series. ArterialAIV lactate difference demonstrated extraction in all conditions, with the exception of the Shunt-Hypo group, during which there was a significant production of lactate from the target myocardium (see the negative value in Table 3 ).

\section{Regional $\mathrm{MVO}_{2}$ and $\mathrm{O}_{2}$ Delivery in the Target Myocardium}

Fig 5 shows the calculated results of regional $\mathrm{MVO}_{2}$ in the target zone. Regional $\mathrm{MVO}_{2}$ significantly $(P=.04)$ decreased with the shunt in place under normotensive conditions compared with the baseline values in association with a decrease in the $\mathrm{O}_{2}$ delivery (Table 3). However, the 
TABLE 3. Segmental oxygen delivery, oxygen extraction, oxygen supply/consumption ratio, and lactate extraction during control, intracoronary shunt, and active-perfusion series of experiments

\begin{tabular}{|c|c|c|c|c|c|}
\hline & \multirow[b]{2}{*}{ Baseline } & \multicolumn{2}{|c|}{ Shunt } & \multicolumn{2}{|c|}{ Perfusion } \\
\hline & & Normotension & Hypotension & Normotension & Hypotension \\
\hline $\mathrm{O}_{2}$ delivery $\left(\mathrm{mL} \mathrm{O}_{2} / \mathrm{min}\right.$ per $\left.100 \mathrm{~g}\right)$ & $13.2 \pm 2.0$ & $5.3 \pm 1.6\left({ }^{*} P=.01\right)$ & $\begin{array}{c}2.0 \pm 0.4\left(^{*} P<.0001\right. \\
\dagger P=.04)\end{array}$ & $21.8 \pm 2.7\left({ }^{*} P=.2\right)$ & $18.3 \pm 1.2\left({ }^{*} P=.046\right)$ \\
\hline $\mathrm{O}_{2}$ extraction $(\%)$ & $45.7 \pm 4.2$ & $41.9 \pm 5.8$ & $\begin{array}{c}78.7 \pm 4.8\left({ }^{*} P<.0001\right. \\
\dagger P<.0001)\end{array}$ & $40.0 \pm 3.8$ & $37.9 \pm 4.3$ \\
\hline $\mathrm{O}_{2} \mathrm{~S} \mathrm{MVO}_{2}$ ratio & $2.6 \pm 0.5$ & $2.7 \pm 0.5$ & $\begin{array}{c}1.3 \pm 0.1\left({ }^{*} P=.016\right. \\
+P=.012)\end{array}$ & $2.6 \pm 0.2$ & $3.3 \pm 0.7$ \\
\hline Lactate extraction (\%) & $31.2 \pm 18.6$ & $31.0 \pm 7.8$ & $\begin{array}{c}-67.4 \pm 17.3\left({ }^{*} P=.005\right. \\
\dagger P=.0008)\end{array}$ & $21.4 \pm 11.1$ & $38.8 \pm 13.6$ \\
\hline
\end{tabular}

*Significant versus baseline.

tSignificant versus normotension in the same series.

oxygen supply/consumption ratio $\left(\mathrm{O}_{2} \mathrm{~S} / \mathrm{MVO}_{2}\right)$ averaged 2.7 \pm 0.5 , which was comparable with the baseline value (Table 3). Systemic hypotension with the shunt caused a further decrease in $\mathrm{MVO}_{2}$, and oxygen extraction increased nearly 2-fold (Table 3). The $\mathrm{O}_{2} \mathrm{~S} / \mathrm{MVO}_{2}$ ratio decreased to $1.3 \pm$ 0.1 , and transmyocardial lactate extraction converted to production (Table 3 ). In contrast, oxygen variables remained at or exceeded baseline values in the active-perfusion series during both normotensive and hypotensive conditions.

\section{Discussion}

The effect of temporary segmental ischemia on the working heart depends on the duration of ischemia, the extent of the ischemic area, the presence of collateral circulation, and the oxygen supply-to-demand balance in the involved myocardium. Although some studies have reported no adverse effects from transient occlusion of the target vessel, ${ }^{1,16}$ others have demonstrated myocardial damage of varying degrees during OPCAB. ${ }^{3,4}$ Additionally, experimental studies have reported persistent contractile dysfunction, endothelial injury, and apoptosis as physiologic consequences of brief coronary occlusion. ${ }^{17-19}$ These consequences have prompted the use of several strategies, such as a "proximal first" approach, intraluminal coronary shunts, and ischemic preconditioning of the target myocardium, especially in multivessel OPCAB, to reduce the duration and consequences of ischemia. ${ }^{4,11,20,21}$ In this regard the PADCAB technique is one of the options to avoid ischemia induced by temporary coronary occlusion. ${ }^{12}$ Although the technique was originally applied to graft conduits after the completion of the distal anastomosis, the target coronary artery can be perfused directly with the aid of an intraluminal device, as was applied in the present study.

In the present study we tested the potential benefits of active perfusion over passive coronary perfusion through an intracoronary shunt in a canine OPCAB model. The outer diameter of the shunt used in our study was $2.25 \mathrm{~mm}$, which is commonly used for clinical cases and which was approximately $90 \%$ of the diameter of the native vessel. The myocardial blood flow during shunt interposition was significantly impeded; myocardial blood flow was further impaired by systemic hypotension, especially to the subendocardium. This maldistribution of blood flow with the shunt was associated with a significant decrease in $\mathrm{O}_{2}$ delivery, $\mathrm{O}_{2}$ consumption, and segmental function in the target myocardium. With normal blood pressure, $\mathrm{O}_{2}$ delivery and $\mathrm{O}_{2}$ consumption decreased by over $50 \%$ during interposition of the intracoronary shunt. However, the $\mathrm{O}_{2}$ supply/consumption ratio and $\mathrm{O}_{2}$ extraction were not altered, and there was no net change in lactate extraction that would indicate an ischemic condition. ${ }^{22}$ With superimposed hypotension and shunting, $\mathrm{O}_{2}$ delivery was further decreased, and $\mathrm{O}_{2}$ extraction increased nearly 2 -fold. The $\mathrm{O}_{2}$ supply/consumption ratio decreased to unity $(1.3 \pm 0.1)$, and transmyocardial lactate extraction converted to production without a change in the arterial lactate concentration. Therefore under normotensive conditions, the shunt reduced $\mathrm{O}_{2}$ delivery and contractile function in similar proportion without ischemia, whereas during hypotension, $\mathrm{O}_{2}$ delivery was reduced to the point of limiting $\mathrm{O}_{2}$ supply and consequently inducing ischemia. In contrast to the shunt series, oxygen variables remained or exceeded baseline conditions during active perfusion with normal blood pressure. Moreover, hypotension did not induce a decrease in $\mathrm{O}_{2}$ delivery (caused by maintained blood flow levels) or an increase in $\mathrm{O}_{2}$ extraction, and the $\mathrm{O}_{2}$ delivery/consumption ratio remained at the baseline level. Consequently, lactate extraction was maintained with active perfusion, even during hypotensive conditions.

Unimpaired contractile function requires that oxygen availability equals or exceeds oxygen demand. A decrease 
in oxygen supply will downregulate contractile function to that level supported by the oxygen supply so that the oxygen supply/demand (consumption) ratio will be greater than or equal to 1.0. In our data, with interposition of the shunt, transmural blood flow decreased by $67 \%$ with a correspondingly equivalent decrease in contractile function, so the $\mathrm{O}_{2}$ supply/consumption ratio was not altered. The lack of ischemia was supported by an absence of lactate production by the target myocardium. Therefore a condition similar to hibernation was created by the shunt. ${ }^{23,24}$ However, hypotension, which may also be encountered during vertical displacement of the heart to visualize posterior target vessels, ${ }^{5,6,25}$ or during ventricular compression by stabilization devices, exacerbated the decrease in blood flow, with the greatest decrease being observed in the subendocardium (86\% decrease from baseline). The subendocardium is particularly vulnerable to oxygen supply and demand imbalances. ${ }^{27}$ Therefore the decrease in myocardial blood flow observed in the present study during hypotension with the shunt was likely sufficient to create myocardial ischemia, as evidenced by lactate production from the target myocardium, and an $\mathrm{O}_{2}$ supply/consumption ratio of approximately 1.0 indicates supply limitation. The additional decrease in target area contractile function may have been due to the combined effects of impaired oxygen delivery and ventricular unloading created by caval occlusion. In contrast, selective PADCAB perfusion maintained adequate myocardial blood flow and oxygen supply both under normotensive and hypotensive conditions and therefore effectively disconnected the blood supply from variations in passive perfusion pressure.

The present data from the noninvolved (LCx-perfused) zone demonstrated that there was no change in the RMBF or segmental function, regardless of the methods used to perfuse the LAD area under normotensive conditions. However, during hypotension induced by partial caval occlusion, segmental function decreased equally in both perfusion modalities. The decrease in function in the noninvolved segment during hypotension is likely caused by preload reduction and ventricular unloading. Hence part of the decrease in function in the target (LAD) myocardium is likely attributed to preload reduction, whereas a portion is due to insufficient blood flow to support function.

There is an apparent discrepancy between the oxygen consumption and the contractile work achieved in the target vessel during hypotension in the active perfusion set of data: the decrease in regional contractile function far exceeded the decrease in oxygen consumption. Relative to the preceding normotensive period, hypotension was associated with a $50 \%$ decrease in peak left ventricular systolic pressure and a $60 \%$ decrease in systolic shortening, and oxygen consumption decreased by only $25 \%$. Accordingly, the oxygen supply/demand ratio was higher during hypotension than during normotension. However, the relatively small decrease in oxygen consumption during hypotension is consistent with a comparable decrease in pressure-rate product, which declined by $28 \%$ from the normotensive value. This index correlates well with myocardial oxygen consumption as long as there are no significant changes in inotropic state. ${ }^{28}$ The increase in heart rate during hypotension counterbalanced the decrease in left ventricular pressure and mitigated the decrease in pressure-rate product. Although systolic shortening also decreased to a relatively large extent (approximately 50\%), the degree of contractile shortening is a relatively minor determinant of overall myocardial oxygen demands. ${ }^{29,30}$ Hence the oxygen consumption during hypotension was consistent with the combined pressure and heart-rate determinants of myocardial oxygen demands predicted by the pressure-rate product.

The strategy to induce systemic hypotension was designed to simulate the influence of vertical displacement of the beating heart, which is required for exposure of posterior LCx branches. Hemodynamic changes during vertical displacement of the beating heart occur by means of outflow tract obstruction, and compressive forces imposed by the tissue stabilizers have been previously investigated. ${ }^{5,6}$ The observed decrease in coronary blood flow, stroke volume, and systemic pressure can be successfully reversed by augmented ventricular preloads. However, in broader terms the physiologic consequences of reduced coronary perfusion pressure observed with hypotension are also applicable to severe stenosis of the target vessel in which perfusion pressure and flow distal to the lesion are impeded. The hypotension maneuver used in the present study similarly caused a decrease in the myocardial blood flow, segmental work, and systemic pressure. We interpret the decrease in systolic shortening during hypotension to be due to the combined effects of preload reduction and inadequate blood flow. Inadequate blood flow (supply-demand mismatch) is suggested by lactate release from the myocardium served by the LAD coronary artery.

From the clinical point of view, the use of intracoronary shunts is better than simple occlusion during anastomosis in providing blood supply to avoid ischemia of the distal segments. The present study has demonstrated the possible advantage of selective active perfusion of target myocardium over the use of intracoronary shunts, especially when systemic hypotension is encountered in a planned or unplanned manner. Currently, the PADCAB technique has been reported for perfusion through the grafted vessels to eliminate the risk of ischemia or hypoperfusion of grafted segments during subsequent anastomosis. However, the target coronary artery, which is being anastomosed, could be perfused directly with the use of an intraluminal device. Although segmental function under systemic hypotension was due to a combination of preload 
reduction and limitation in oxygen delivery and was not maintained by selective perfusion, ischemia was avoided, and adequate perfusion was maintained.

The impaired delivery of blood through the shunt was observed in a model of unobstructed coronary artery blood flow. In coronary arteries with significant disease, the perfusion pressure distal to the stenotic lesion may be lower than that in the aorta or in the normal coronary artery. In this situation the impedance of blood flow by the shunt may be greater, thereby potentially creating ischemia rather than hibernation, especially during periods of hypotension. The additional impairment of blood flow by coronary lesions should be examined with models of stenosis of varying degrees. However, in chronically stenotic coronary arteries, the development of collateral blood supply occurring in chronic ischemia may offset the mismatch in oxygen supply versus demand observed in the present model of acute ischemia. Furthermore, the index of regional contractile function (systolic shortening) used in the present study is not load independent; that is, the percentage of systolic shortening will increase with afterload reduction or a decrease in heart rate or will decrease with preload reduction (as observed during the hypotension interval) independent of changes in contractility. We interpreted a decrease in systolic shortening fraction as dysfunction only when it was associated with localized lactate release. However, further studies should use load-independent indices to investigate the relationship between coronary blood flow, function, and metabolism during interposition of the shunt. Finally, the injection of microspheres into the perfusion line was made in the absence of a device to ensure adequate mixing with the blood. The possible axial streaming of the microspheres may have decreased the number of microspheres withdrawn from the side port of the perfusion line and thereby may have led to an overestimation of transmural blood flow. Second, axially streaming microspheres may have favored a greater distribution of microspheres to the subendocardial tissue.

In summary, the present study demonstrated that blood flow through an appropriately sized coronary shunt is inadequate to meet oxygen demands necessary to maintain regional contractile activity but causes hibernation rather than ischemia. However, ischemia is observed with the shunt during hypotension. The impaired delivery of myocardial blood flow caused by the intracoronary shunts and hypotension is overcome by means of selective and active perfusion of the target vessel with a bladder-based pump that makes perfusion independent of upstream blood pressure. This novel assist strategy for OPCAB grafting can be used in cases requiring prolonged periods of ischemia or ischemia in multiple target areas and for patients who are likely to experience systemic hypotension at some point during the surgical procedure. Further studies confirming the clinical benefits of this active-perfusion strategy and the length of time that a shunt can be used without producing unfavorable effects should be conducted before adoption in clinical practice.

We thank Jill Robinson, Sara Katzmark, L. Susan Schmarkey for their technical assistance, and Laurie Berleg for word processing.

\section{References}

1. Arom KV, Flavin TF, Emery RW, Kshettry VR, Janey PA, Petersen RJ. Safety and efficacy of off-pump coronary artery bypass grafting. Ann Thorac Surg. 2000;69:704-10.

2. Tasdemir O, Vural KM, Karagoz H, Bayazit K. Coronary artery bypass grafting on the beating heart without the use of extracorporeal circulation: review of 2052 cases. J Thorac Cardiovasc Surg. 1998; 116:68-73.

3. Lockowandt UL, Owall A, Franco-Cereceda A. Myocardial outflow of prostacyclin in relation to metabolic stress during off-pump coronary artery bypass grafting. Ann Thorac Surg. 2000;70:206-11.

4. Bonatti J, Hangler H, Hormann C, Mair J, Falkensammer J, Mair P. Myocardial damage after minimally invasive coronary artery bypass grafting on the beating heart. Ann Thorac Surg. 1998;66:1093-6.

5. Grundeman PF, Borst C, van Herwaarden JA, Mansvelt Beck HJ, Jansen EW. Hemodynamic changes during displacement of the beating heart by the Utrecht Octopus method. Ann Thorac Surg. 1997;63:S88-92.

6. Grundeman PF, Borst C, van Herwaarden JA, Verlaan CW, Jansen EW. Vertical displacement of the beating heart by the Octopus Tissue Stabilizer: influence on coronary flow. Ann Thorac Surg. 1998;65: 1348-52.

7. Waldenberger FR, Haisjackl M, Holinski S, Lengsfeld M, Konertz W. Centrifugal pumps as left ventricular assist for coronary revascularization on a beating heart. Artif Organs. 1998;22:698-702.

8. Geskes GG, Dekker AL, van der Veen FH, Cramers AA, Maessen JG, Shoshani D, et al. The enabler right ventricular circulatory support system for beating heart coronary artery bypass graft surgery. Ann Thorac Surg. 1999;68:1558-61.

9. Lucchetti V, Capasso F, Caputo M, Grimaldi G, Capece M, Brando G, et al. Intracoronary shunt prevents left ventricular function impairment during beating heart coronary revascularization. Eur $J$ Cardiothorac Surg. 1999;15:255-9.

10. van Aarnhem EEHL, Nierich AP, Jansen EW. When and how to shunt the coronary circulation in off-pump coronary artery bypass grafting. Eur J Cardiothorac Surg. 1999;16:S2-6.

11. Dapunt OE, Raji MR, Jeschkeit S, Dhein S, Kuhn-Regnier F, Sudkamp M, et al. Intracoronary shunt insertion prevents myocardial stunning in a juvenile porcine MIDCAB model absent of coronary artery disease. Eur J Cardiothorac Surg. 1999;15:173-9.

12. Guyton RA, Thourani VH, Puskas JD, Shanewise JS, Steele MA, Palmer-Steele CL, et al. Perfusion-assisted direct coronary artery bypass: selective graft perfusion in off-pump cases. Ann Thorac Surg. 2000;69:171-5.

13. Vinten-Johansen J, Johnston WE, Crystal GJ, Mills SA, Santamore WP, Cordell AR. Validation of local venous sampling within the at risk left anterior descending artery vascular bed in the canine left ventricle. Cardiovasc Res. 1987;21:646-51.

14. Nakanishi K, Vinten-Johansen J, Lefer DJ, Zhao Z, Fowler WCd, McGee DS, et al. Intracoronary L-arginine during reperfusion improves endothelial function and reduces infarct size. Am J Physiol. 1992;263:H1650-8.

15. Kowallic P, Schulz R, Guth BD. Measurement of regional myocardial blood flow with multiple colored microspheres. Circ Res. 1991;83: 974-82.

16. Ascione R, Lloyd CT, Gomes WJ, Caputo M, Bryan AJ, Angelini GD. Beating versus arrested heart revascularization: evaluation of myocardial function in a prospective randomized study. Eur J Cardiothorac Surg. 1999;15:685-90.

17. Thourani VH, Nakamura M, Duarte IG, Bufkin BL, Zhao ZQ, Jordan JE, et al. Ischemic preconditioning attenuates postischemic coronary artery 
endothelial dysfunction in a model of minimally invasive direct coronary artery bypass grafting. J Thorac Cardiovasc Surg. 1999;117:383-9.

18. Wang NP, Bufkin BL, Nakamura M, Zhao ZQ, Wilcox JN, HewanLowe $\mathrm{KO}$, et al. Ischemic preconditioning reduces neutrophil accumulation and myocardial apoptosis. Ann Thorac Surg. 1999;67: 1689-95.

19. Bufkin BL, Shearer ST, Vinten-Johansen J, Duarte IG, Thourani VH, Nakamura M, et al. Preconditioning during simulated MIDCABG attenuates blood flow defects and neutrophil accumulation. Ann Thorac Surg. 1998;66:726-32.

20. Chitwood WR Jr, Wixon CL, Elbeery JR, Francalancia NA, Lust RM. Minimally invasive cardiac operation: adapting cardioprotective strategies. Ann Thorac Surg. 1999;68:1974-7.

21. Flameng WJ. Role of myocardial protection for coronary artery bypass grafting on the beating heart. Ann Thorac Surg. 1997;63:S1822.

22. Weil MH, Afifi AA. Experimental and clinical studies on lactate and pyruvate as indicators of the severity of acute circulatory failure (shock). Circulation. 1970;41:989-1001.

23. Bristow JD, Arai AE, Anselone CG, Pantely GA. Response to myocardial ischemia as a regulated process. Circulation. 1991;84:2580-7.
24. Downing SE, Chen V. Myocardial hibernation in the ischemic neonatal heart. Circ Res. 1990;66:763-72.

25. Grundeman PF, Borst C, Verlaan CW, Meijburg H, Moues CM, Jansen EW. Exposure of circumflex branches in the tilted, beating porcine heart: echocardiographic evidence of right ventricular deformation and the effect of right or left heart bypass. J Thorac Cardiovasc Surg. 1999;118:316-23.

26. Burfeind WR Jr, Duhaylongsod FG, Samuelson D, Leone BJ. The effects of mechanical cardiac stabilization on left ventricular performance. Eur J Cardiothorac Surg. 1998;14:285-9.

27. Hoffman JIE, Buckberg GD. Transmural variation in myocardial perfusion. Prog Cardiol. 1976;5:37-89.

28. Vinten-Johansen J, Duncan HW, Finkenberg JG, Hume MC, Robertson JM, Barnard RJ, et al. Prediction of myocardial $\mathrm{O} 2$ requirements by indirect indices. Am J Physiol. 1982;243:H862-8.

29. Taylor RR, Cingolani HE, Graham TP, Clancy RL. Myocardial oxygen consumption, left ventricular fibre shortening and wall extension. Cardiovasc Res. 1967;1:219-28.

30. Gayheart PA, Vinten-Johansen J, Johnston WE, Hester TO, Cordell AR. Oxygen requirements of the dyskinetic myocardial segment. Am J Physiol. 1989;257:H1184-91.

\section{Bound volumes available to subscribers}

Bound volumes of The Journal of Thoracic and Cardiovascular Surgery are available to subscribers (only) for the 2002 issues from the Publisher, at a cost of $\$ 134.00$ for domestic, $\$ 165.85$ for Canadian, and $\$ 155.00$ for international subscribers for Vol 123 (January-June) and Vol 124 (July-December). Shipping charges are included. Each bound volume contains a subject and author index and all advertising is removed. The binding is durable buckram with the Journal name, volume number, and year stamped in gold on the spine. Payment must accompany all orders. Contact Mosby, Subscription Customer Service, 6277 Sea Harbor Dr, Orlando, FL 32887, USA; phone 800-654-2452 or 407-345-4000.

Subscriptions must be in force to qualify. Bound volumes are not available in place of a regular Journal subscription. 